UDC 343.139

LBC 67.410.2

\title{
PARTING WORDS OF THE CHAIRMAN OF A JURY TRIAL: LEGAL AND MORAL IMPLICATIONS
}

\author{
Darya O. Chistilina \\ South-West State University, Kursk, Russian Federation
}

\begin{abstract}
Introduction: a jury trial is a special form of criminal proceedings. It has a unique structure, as well as some procedural features in the course of judicial investigation. At the same time, it is indisputable that the chairman has organizational powers and is the link between the jurors and the rest of the participants in the process. In this regard, we should not underestimate his/her influence on the board. The chairman's parting words is an effective mechanism that forms the inner conviction of the jurors. The main purpose is to study the order of pronouncing and the internal structure of the chairman's parting words, as well as to study its moral implications. Methods: the research methodology includes both the general scientific methods and the specific legal research methods. Results: a number of issues related to the chairman's parting words remain unresolved in the scientific literature and in the law enforcement activities. Despite the fact that the law lists its main substantive parts, but in practice the structure of parting words is not uniform. In addition, the chairmen often include in the text such substantive elements that are subsequently challenged by the parties and are a substantial cause of appeal against sentences handed down by a jury. It should be noted that in some foreign countries the text of the parting words is standardized, which excludes some procedural disputes on this matter. In addition, at the stage of pronouncing the words of encouragement by the chairman there appear some questions that need to be specified in the law. The article contains the proposals to improve the current legislation in this area, as well as the recommendations of a moral nature for judges. Conclusions: thus, the chairman's parting words can have a significant impact on the decision taken by the jury, so it is necessary to develop at the legislative level uniform detailed requirements for its content, as well as the behavior of the chairman during his/her speech.
\end{abstract}

Key words: jury court, parting words, verdict, competition, chairman.

Citation. Chistilina D.O. Parting Words of the Chairman of a Jury Trial: Legal and Moral Implications. Legal Concept, 2018, vol. 17, no. 3, pp. 121-125. DOI: https://doi.org/10.15688/lc.jvolsu.2018.3.17

УДК 343.139

ББК 67.410 .2

\section{НАПУТСТВЕННОЕ СЛОВО ПРЕДСЕДАТЕЛЬСТВУЮЩЕГО В СУДЕ С УЧАСТИЕМ ПРИСЯЖНЫХ ЗАСЕДАТЕЛЕЙ: ПРАВОВОЕ И НРАВСТВЕННОЕ СОДЕРЖАНИЕ}

\author{
Дарья Олеговна Чистилина \\ Юго-Западный государственный университет, г. Курск, Российская Федерация
}

Введение: суд с участием присяжных заседателей является особой формой уголовного судопроизводства. Он отличается уникальной структурой, а также некоторыми процессуальными особенностями в ходе судебного следствия. В то же время бесспорно, что председательствующий обладает организационными полномочиями и является связующим звеном между присяжными заседателями и остальными участниками процесса. В связи с этим нельзя недоценивать его влияние на коллегию. Напутственное слово председательствующего является действенным механизмом, формирующим внутреннее убеждение присяжных заседателей. Основной целью является исследование порядка произнесения и внутренней структуры напутственного слова председательствующего, а также изучение его нравственного содержания. Методы: методология исследования включает как общенаучные методы, так и специфические юридические методы иссле- 
дования. Результаты: в научной литературе и в правоприменительной деятельности до сих пор остаются неразрешенными ряд вопросов, связанных с напутственным словом председательствующего. Несмотря на то, что в законе перечислены его основные содержательные части, однако на практике структура напутственного слова не отличается единообразием. Кроме того, зачастую председательствующие включают в его текст такие содержательные элементы, которые впоследствии оспариваются сторонами и являются существенным поводом для обжалования приговоров, вынесенных судом с участием присяжных заседателей. Отметим, что в некоторых зарубежных странах текст напутственного слова стандартизирован, что исключает некоторые процессуальные споры по этому поводу. Помимо этого, на этапе произнесения напутственного слова председательствующим возникают некоторые вопросы, которые требуют конкретизации в законе. В статье содержатся предложения по совершенствованию действующего законодательства в данной сфере, а также рекомендации нравственного характера для судей. Выводы: таким образом, напутственное слово председательствующего может оказать значительное влияние на принимаемое присяжными заседателями решение, поэтому необходимо на законодательном уровне разработать единые детальные требования к его содержанию, а также поведению председательствующего во время его произнесения.

Ключевые слова: суд с участием присяжных заседателей, напутственное слово, вердикт, состязательность, председательствующий.

Цитирование. Чистилина Д. О. Напутственное слово председательствующего в суде с участием присяжных заседателей: правовое и нравственное содержание // Legal Concept = Правовая парадигма. - 2018. T. 17, № 3. - C. 121-125. - DOI: https://doi.org/10.15688/lc.jvolsu.2018.3.17

\section{Введение}

Перед удалением присяжных заседателей в совещательную комнату председательствующий обращается к ним с напутственным словом, которое представляет собой краткое изложение обвинения, исследованных в суде доказательств и позиций обвинения и защиты, а также юридическое наставление присяжным заседателям. Бесспорно, что напутственное слово имеет текстуальную привязку к обвинительному заключению, но председательствующий должен так изложить обстоятельства дела, чтобы у присяжных заседателей не сложилось впечатление, что виновность подсудимого доказана [4, с. 75-79]. Континентальная модель, в отличие от англосаксонской, не предполагает ссылки на закон, а ограничивается лишь инструкцией по организационным вопросам [9, с. 859-872].

По той причине, что обжаловать приговоры, вынесенные судом с участием присяжных заседателей, можно лишь по формальным основаниям, особое внимание следует обратить на текст напутственного слова. В некоторых странах есть обязательные образцы напутствия, что исключает предвзятость профессионального судьи (например, в некоторых штатах США) [6, с. 61-64]. В России же законодатель ограничился перечислением в ст. 340 УПК РФ основных составляющих напутственного слова, оставляя свобо- ду для творчества председательствующему. В связи с этим в суды поступает все больше жалоб именно на содержание напутственного слова. Так, в некоторых из них указано, что председательствующий в напутственном слове проявил заинтересованность в исходе дела, высказал свою точку зрения о виновности лица, критиковал позицию стороны защиты, давал профессиональную оценку доказательств и т. д. [1, с. 7].

\section{Порядок произнесения напутственного слова председательствующим}

В российском уголовном процессе напутственное слово произносится именно после этапа постановки вопросов, что позволяет председательствующему разъяснить присяжным заседателям суть поставленных перед ними вопросов и сразу дать им необходимые пояснения. Однако краткое напутственное слово может произноситься председательствующим после внесения изменений в вопросный лист, а также повторяться после возобновления судебного следствия. Данные случаи произнесения напутствия связаны с объективной необходимостью дачи присяжным дополнительных разъяснений [3, с. 497-503].

Главная цель напутственного слова заключается в способствовании уяснению присяжными заседателями существа дела в 
объективном ключе, без явного превалирования позиции одной из сторон, и предостережении их от вынесения неправосудного вердикта. Заметим, что при произнесении напутственного слова председательствующему запрещается в какой-либо форме выражать свое мнение по вопросам, поставленным перед коллегией присяжных заседателей, во избежание оказания тем самым влияния на их решение, то есть председательствующий должен быть объективен и беспристрастен [10]. Как в дореволюционной литературе, так и в настоящее время существуют различные точки зрения по этому вопросу [7, с. 556-562]. На наш взгляд, все же стоит придерживаться положений действующего УПК РФ, поскольку председательствующий в глазах присяжных представляется лицом, заслуживающим уважения, более того, они ассоциируют себя с ним, поэтому не исключено, что его мнение окажет значительное влияние на выносимый присяжными заседателями вердикт.

Речь председательствующего, во-первых, должна быть направлена исключительно на присяжных заседателей, во-вторых, быть объективной в плане изложения положений закона и фактических обстоятельств дела; в-третьих, быть информативной, в-четвертых, соответствовать требованиям по содержанию ст. 340 УПК РФ [2, с. 243-252]. Кроме того, она обязательна для присяжных, может быть оспорена сторонами, вследствие чего дополнена и уточнена.

Текст напутственного слова председательствующий может заготовить заранее или произнести спонтанно. Это зависит от личных предпочтений судьи. В любом случае содержание напутственного слова должно быть подробно изложено в протоколе судебного заседания [10]. Причем наличие в тексте средств выразительности, элементов разговорного стиля, эмоциональных высказываний зачастую не могут быть расценены как предвзятость судьи. Конечно, если они не выходят за рамки закона и намеренно не используются как средства воздействия.

Напутственное слово, как правило, излагается письменно в виде отдельного документа и прилагается к протоколу судебного заседания либо его содержание излагается в протоколе судебного заседания, однако его текст не передается присяжным в совещательную комнату, что критикуют многие исследователи в данной области. Они предполагают, что напутственное слово, кроме всего прочего, содержит и ряд руководящих, организационных положений, помогающих присяжным действовать в соответствии с законом в совещательной комнате. В связи с этим считаем целесообразным, чтобы текст напутствия передавался присяжным, ведь, по сути, он должен содержать лишь констатацию исследованных в ходе судебного следствия фактов, поэтому с его помощью невозможно оказать давление на присяжных.

Напутственное слово состоит из следующих частей:

1) вступление - может содержать благодарность присяжным заседателям за внимательное исследование материалов дела, объяснение председательствующим значения напутственного слова, вердикта и т. д.;

2) изложение сути предъявленного обвинения, которое соответствует последней версии, представленной прокурором;

3) разъяснение уголовного закона, которым предусматривается уголовная ответственность за данное преступление, содержащее как конкретные примеры из рассматриваемого уголовного дела для большей наглядности, так и более общие положения [11, c. 230-238];

4) напоминание председательствующим основного содержания доказательств. Причем он не может ограничиться лишь их перечислением, а должен еще раз разъяснить присяжным их суть. В законе нет строго фиксированного порядка изложения доказательств, однако целесообразно следовать принципу состязательности и говорить сначала об обвинительных, а затем об оправдательных доказательствах [5, с. 97-103];

5) изложение председательствующим позиции государственного обвинителя и защитника без явного благоприятствования одной из сторон. Причем наиболее приемлем, на наш взгляд, подробный рассказ, а не номинальное напоминание, чтобы присяжные поняли, в чем конкретно отличаются позиции сторон. Например, можно проанализировать вопросный лист с точки зрения существующих противоречий между защитником и государственным обвинителем; 
6) разьяснение председательствующим правил оценки доказательств и основных принципов уголовного процесса. Данная часть напутствия наиболее стандартизирована. Лучше всего начать с пояснения присяжным заседателям сути принципа презумпции невиновности со всеми вытекающими оттуда последствиями. Более того, судья должен упомянуть о том, что ни одно из доказательств не имеет преимущества перед другими, доказательства должны оцениваться в совокупности по внутреннему убеждению, а вердикт должен быть основан только на тех доказательствах, которые были исследованы в ходе судебного следствия. Если же подсудимый отказался давать показания, то это отнюдь не свидетельствует о его виновности. Несмотря на то, что присяжные заседатели оценивают фактическую сторону доказательств, однако не лишним будет упоминание о юридической составляющей их оценки;

7) организационные вопросы, касающиеся правил совещания и вынесения вердикта. Председательствующий объясняет порядок совещания присяжных заседателей, роль и основные задачи старшины, упоминает о некоторых ограничениях, а также разъясняет порядок назначения наказания в случае признания ими подсудимого заслуживающим снисхождения, приводя примеры исчисления сроков. В заключение председательствующий напоминает содержание данной присяжными присяги [8, с. 77-105].

Отметим, что председательствующий при произнесении напутственного слова не может ставить под сомнение правдивость показаний участников процесса, а также компетентность эксперта и специалиста.

\section{Выводы}

Председательствующему следует следить не только за содержательной частью напутственного слова, но и за собственной мимикой и жестами, которые должны быть сдержанными и явно не свидетельствовать о благоприятствовании одной из сторон. Стороны вправе заявить возражения по содержанию напутственного слова по мотивам нарушения принципа объективности и беспристрастности в присутствии присяжных заседателей. В их же присутствии председательствующий излагает свое решение по заявленным сторонами возражениям.

Таким образом, целью произнесения напутственного слова является оказание помощи присяжным в решении поставленных перед ними вопросов, поэтому председательствующий должен быть особенно внимателен к деталям при его составлении и произнесении.

\section{СПИСОК ЛИТЕРАТУРЫ}

1. Александров, А. Напутственное слово: история одного дела / А. Александров, А. Босов // ЭЖ-Юрист. - 2013. - № 16. - С. 7.

2. Астафьев, А. Ю. Напутственное слово председательствующего в суде присяжных: лингвоюридические аспекты / А. Ю. Астафьев // Вестник Воронежского государственного университета. Серия: Право. - 2017. - № 2. - С. 243-252.

3. Беляев, М. В. Напутственное слово председательствующего в суде с участием присяжных: быть или не быть? / М. В. Беляев // Ученые записки Казанского университета. Серия: Гуманитарные науки. - 2017. - Т. 159, № 2. - С. 497-503.

4. Босов, А. Е. Доказывание - коммуникация в суде с участием присяжных заседателей / А. Е. Босов, А. О. Машовец // Уголовное право. - 2015. № 6. - C. 75-79.

5. Каневский, Б. Напутственное слово председательствующего с точки зрения речевых актов / Б. Каневский, А. Босов // Уголовное право. - 2013. № 2. - С. 97-103.

6. Коломенская, С. А. Напутственное слово председательствующего в уголовном процессе США / С. А. Коломенская // Российский судья. 2016. - № 8. - C. 61-64.

7. Максимова, Т. Ю. Роль председательствующего в формировании у присяжных внутреннего убеждения по делу и недопущении незаконного воздействия на них: сравнительно-правовой анализ норм Устава уголовного судопроизводства 1864 года и УПК РФ / Т. Ю. Максимова // Актуальные проблемы российского права. - 2014. - № 4. C. $556-562$.

8. Насонов, С. А. Напутственное слово председательствующего в суде присяжных / С. А. Насонов. - М. : Р. Валент, 2006. -304 c.

9. Насонов, С. А. Напутственное слово председательствующего судьи в исторических моделях производства в суде присяжных / С. А. Насонов // LEX RUSSICA. - 2011. - № 5. - C. 859-872.

10. Постановление Пленума Верховного Суда Российской Федерации от 22 ноября 2005 г. «О некоторых вопросах применения судами уголовнопроцессуальных норм, регламентирующих произ- 
водство в суде присяжных» // Российская газета. 2005. - № 272 .

11. Хатуаева, В. В. Особенности формирования вопросного листа и напутственного слова председательствующего при рассмотрении уголовного дела с участием присяжных заседателей (практика Воронежского областного суда) / В. В. Хатуаева, М. А. Авдеев // Ленинградский юридический журнал. - 2016. - № 3. - С. 230-238.

\section{REFERENCES}

1. Aleksandrov A., Bosov A. Naputstvennoe slovo: istoriya odnogo dela [A Parting Word: the Story ofOne Case]. EZH-Yurist, 2013, no. 16, p. 7.

2. Astafyev A.Yu. Naputstvennoe slovo predsedatelstvuyushchego $\mathrm{v}$ sude prisyazhnykh: lingvoyuridicheskie aspekty [A Parting Word of the Presiding Judge of the Jury: Linguistic and Legal Aspects]. Vestnik Voronezhskogo gosudarstvennogo universiteta. Seriya: Pravo, 2017, no. 2, pp. 243-252.

3. Belyaev M.V. Naputstvennoe slovo predsedatelstvuyushchego $\mathrm{v}$ sude $\mathrm{s}$ uchastiem prisyazhnykh: byt ili ne byt? [A Parting Word of the Presiding Judge of the Jury: to Be or not to Be?]. Uchenye zapiski Kazanskogo universiteta. Seriya: Gumanitarnye nauki, 2017, vol. 159, no. 2, pp. 497-503.

4. Bosov A.E., Mashovets A.O. Dokazyvanie kommunikatsiya $\mathrm{v}$ sude $\mathrm{s}$ uchastiem prisyazhnykh zasedateley [The Proof is the Communication in Court with the Participation of Jurors]. Ugolovnoe pravo, 2015, no. 6, pp. 75-79.

5. Kanevskiy B., Bosov A. Naputstvennoe slovo predsedatelstvuyushchego s tochki zreniya rechevykh aktov [A Parting Word of the Presiding Judge from the Viewpoint of Speech Acts Theory]. Ugolovnoe pravo, 2013, no. 2, pp. 97-103.

6. Kolomenskaya S.A. Naputstvennoe slovo predsedatelstvuyushchego $\mathrm{v}$ ugolovnom protsesse SSHA [A Parting Word of the Presiding Judge in the Criminal Proceedings of the USA]. Rossiyskiy sudya, 2016, no. 8, pp. 61-64.
7. Maksimova T.Yu. Rol predsedatelstvuyushchego $\mathrm{v}$ formirovanii u prisyazhnykh vnutrennego ubezhdeniya po delu i nedopushchenii nezakonnogo vozdeystviya na nikh: sravnitelno-pravovoy analiz norm Ustava ugolovnogo sudoproizvodstva 1864 goda i UPK RF [The Role of the Presiding Judge in the Formation of Inner Conviction of the Jury in the Case and the Prevention of Unlawful Influence on Them: a Comparative Legal Analysis of the Provisions of the Charter of Criminal Proceedings of 1864 and the Criminal Procedure Code of the Russian Federation]. Aktualnye problemy rossiyskogo prava, 2014, no. 4, pp. 556-562.

8. Nasonov S.A. Naputstvennoe slovo predsedatelstvuyushchego $v$ sude prisyazhnykh [A Parting Word of the Presiding Judge of the Jury]. Moscow, R.Valent Publ., 2006. 304 p.

9. Nasonov S.A. Naputstvennoe slovo predsedatelstvuyushchego sudyi $\mathrm{v}$ istoricheskikh modelyakh proizvodstva $\mathrm{v}$ sude prisyazhnykh [A Parting Word of the Presiding Judge in Historical Models of Procedure in the Jury]. LEXRUSSICA, 2011, no. 5, pp. 859-872.

10. Postanovlenie Plenuma Verkhovnogo Suda Rossiyskoy Federatsii ot 22 noyabrya $2005 \mathrm{~g}$. «O nekotorykh voprosakh primeneniya sudami ugolovno-protsessualnykh norm, reglamentiruyushchikh proizvodstvo v sude prisyazhnykh» [Decision of the Plenum of the Supreme Court of the Russian Federation of November 22, 2005 'On Some Issues of Application by Courts of Criminal Procedural Norms Regulating the Proceedings in the Jury']. Rossiyskaya gazeta, 2005, no. 272.

11. Khatuaeva V.V., Avdeev M.A. Osobennosti formirovaniya voprosnogo lista i naputstvennogo slova predsedatelstvuyushchego pri rassmotrenii ugolovnogo dela s uchastiem prisyazhnykh zasedateley (praktika Voronezhskogo oblastnogo suda) [Formation of the Question Sheet and the Parting Word of the Presiding Judge at Consideration of Criminal Case with Participation of Jurors (Practice of the Voronezh Regional Court)]. Leningradskiy yuridicheskiy zhurnal, 2016, no. 3, pp. 230-238.

\section{Information about the Author}

Darya O. Chistilina, Postgraduate Student, Department of Criminal Procedure and Criminalistics, SouthWest State University, 50 let Oktyabrya St., 94, 305040 Kursk, Russian Federation, darya-chistilina@yandex.ru.

\section{Информация об авторе}

Дарья Олеговна Чистилина, аспирант кафедры уголовного процесса и криминалистики, Юго-Западный государственный университет, ул. 50 лет Октября, 94, 305040 г. Курск, Российская Федерация, darya-chistilina@yandex.ru. 